\title{
A CONSTITUIÇÃo DAS INDÚSTRIAS KLABIN DE PAPEL E Celulose S/A
}

Nilva Giane Trajano*

Resumo: O presente artigo visa fazer uma análise do processo de funcionamento de uma unidade fabril, no que diz respeito à obtenção de matéria-prima, envolvendo uma trama de relações econômicas e tecnológicas com pequenos proprietários rurais.

Unitermos: história; economia; produtores rurais; indústria; sistema produtivo.

\section{Introdução}

O estudo do processo de constituição das Indústrias Klabin de Papel e Celulose S/A - Divisão Paraná, compreende o período de 1987 a 1993. Visa fazer uma análise de como a indústria se instalou no segundo planalto paranaense constituindo-se no maior complexo produtor de papel da América Latina.

Pretende-se entender o processo de acumulação de capital industrial em relação a um processo de trabalho baseado na utilização de métodos de relacionamento com o pequeno produtor, que garantiram a obtenção de matéria-prima para a transformação industrial.

Este artigo tem por objetivo analisar os motivos que levaram a Família Klabin a montar uma fábrica de papel no interior do Paraná, e os investimentos obtidos para tal realização. O Setor Florestal o qual

\footnotetext{
Professora de História Rede Pública Estadual de Ensino de $1^{\circ}$ e $2^{\circ}$ graus Ortigueira - Paraná
} 
TRAJANO, N.G. A constituição das Indústrias Klabin.

utiliza técnicas especiais para acelerar o crescimento e o desenvolvimento das plantas para a transformação industrial e também os mecanismos utilizados para garantir a participação do produtor dentro do Projeto de Fomento Florestal.

\section{Implantação das Indústrias Klabin de Papel e Celulose S/A.}

Inicialmente as indústrias Klabin foram implantadas em uma propriedade denominada Monte Alegre, composta das antigas fazendas Monte Alegre, Agudo, Anta e Prata num total de 144 mil hectares, localizada no municipio de Tibagi no interior do Paraná.

$O$ antigo dono foi José Felix da Silva, que ao morrer deixou a fazenda para seus filhos e herdeiros, os quais a venderam para uma sociedade anônima: Companhia Agricola e florestal e Estrada de Ferro Monte Alegre, constituida em Paris e que por pouco tempo funcionou na antiga fazenda.

Os membros da Companhia ocuparam-se em pagar missões de estudos para exploraçẫo das minas, florestas, dos pinhais, da agricultura, da colonização com cinco mil (5.000) familias alemãs, da construção da estrada de ferro na Fazenda Monte Alegre (Femandes, 1947:21).

Gastaram quantias imensas, sem executar os planos traçados, indo à falência em 1932. No ano seguinte a Fazenda vai a leilão e quem a adquire é o Banco do Estado do Paraná.

A 20 de outubro de 1934, a familia Klabin compra a Fazenda Monte Alegre com o objetivo de industrializar o pinheiro do Paraná para seus múltiplos ramos, bem como a fabricação de celulose e pasta de madeira e papelão com seus congêneres, estabelecer qualquer indústria extrativa ou não, explorar propriedades agrícolas, empreender atividade de mineração, onde mais convenha à sociedade.

Nesse periodo a produção de papel era subordinada à importação: a celulose e papel-jornal eram importados do Canadá, Estados Unidos, Suécia e Finlândia.(Fernandes, 1974:34).

A dependência do mercado estrangeiro era enorme, e não existia uma politica governamental de incentivos que protegesse a produção. $O$ 
TRAJANO, N.G. A constifuição das Indủstrias Klabin.

desenvolvimento das indústrias de papel processava-se em meio a muitas dificuldades e para ser economicamente viável exigia tecnologia avançada, volume de capital vultuoso e principalmente incentivos governamentais, ou seja, favores especiais às indústrias que se instalassem para a fabricação de papel e celulose.

A preocupação com a indústria papeleira surge com o Estado Novo, o qual abriu novas e extensas fontes de financiamento puiblico(Dean, 1981:228).

Os financiamentos proporcionados às indústrias, tiveram por objetivo aumentar a auto-suficiência do Pais. Fabricando celulose e papel jornal, diminuiram a dependência do mercado estrangeiro.

Para realizar o plano de auto-suficiência na produção do papeljornal e da pasta de papel: Getúlio Vargas prontificou-se pessoalmente a procurar um empresário que se dispusesse a erguer uma nova fábrica de papel. Assis Chateaubriand, dono de maior cadeia de jornais foi o primeiro a ser abordado as declinou da oportunidade(Dean, 1981:229).

Assis Chateaubriand aproveitou o momento e indicou a familia Klabin a Getúlio Vargas. O Presidente aceitou a indicação $e$ encarregou Chateaubriand de ir à São Paulo e oferecer-lhe um empréstimo e a necessária cobertura cambial, bem como um monopólio, se eles se dispusessem a construir a fábrica (Dean, 1981:229).

Os Kabins aceitam o desafio, mas dificilmente poderiam ter recusado; Vargas lhes prometera também um ramal ferroviário e um mercado garantido(Dean, 1981:230).

Como resultado dessa reunião, deu-se um aceleramento na construção da fábrica, constituindo-se na criação de uma indústria que tinha por objetivo incrementar a fabricação de celulose e pasta de papel, empenhando-se em reduzir a dependência brasileira na obtenção de matéria-prima, utilizando-se para isso da madeira existente no interior do Paraná: o pinheiro.

No entanto, a atuação dos Klabins no Paraná, não se limitou à função que desempenhavam no desenvolvimento industrial da região e do Pais. Tomaram-se responsáveis pela dinamização da economia, 
TRAJANO, N.G. A constituição das Indústrias Klabin.

com a implantação de um processo de trabalho que esteve baseado na subsunção real do trabalho ao capital e na utilização de métodos de relacionamento com operariado que garantiram, com exito, a obtenção de alto índices de produtividade, bem como a reprodução do sistema produtivo(Reichell, 1992:101). Tomando-se no maior empreendimento de celulose e papel; a maior unidade do setor da América Latina.

\section{Independência do Papel}

Quando a fábrica começou a funcionar, em 1946, utilizava como matéria prima a madeira do Pinheiro (Araucária angustifólia), para a produção do papel de imprensa e da celulose.

Mas antes mesmo da fábrica começar a funcionar, já existia a preocupação com a quantidade de madeira existente dentro da fazenda Monte Alegre, e por quanto tempo esta seria suficiente, para isso foi criado, em 1941, o Setor Florestal da Klabin Paraná, com a finalidade de suprir o abastecimento da matéria-prima da fábrica. Começaram com o reflorestamento da araucária e de eucalipto, simultaneamente pesquisando espécies que pudessem se adaptar melhor ao clima da região.

Foram introduzidas em 1951, as espécies Pints taeda e Pinus eliotti, que apresentaram um crescimento superior à araucária tomando-se viável economicamente

O Setor Florestal utiliza-se da tecnologia e cria mecanismos para obter da natureza um aumento na produção, além disso desenvolve projetos como o de Fomento Florestal para aumentar as áreas plantadas e desenvolver o progresso da indústria.

Destaco aqui a opinião de Jozimar Paes de Almeida (1988:62).pois também analisa o processo de apropriação da natureza pelo sistema capitalista:

O aumento da produção na agricultura pode ser realizado de várias formas. $A$ primeira diz respeito d̀ ampliação do espaço plantado, considerando-se que a 
TRAJANO, N.G. A constituị̧ão das Indústrias Klabin.

área acrescida seja provida de terras no minimo de igual fertilidade. $O$ aumento na produção é proporcional à quantidade de novas terras integradas.

Uma segunda forma poderia ser alcançada com um aumento no potencial de produtividade ligado, em primeiro lugar, à fertilidade do solo e, em segundo, a um aumento da velocidade no ciclo germinativo e de maturação da planta (revolução genética), objetivando aumentar a quantidade de matéria bruta (vegetais) dentro do mesmo espaço de tempo em que se produzia naturalmente.

O Setor de Pesquisa, mantém continuo programa de pesquisa na área florestal, analisando espécies florestais de interesse econômico, desenvolvendo técnicas de melhoramento genético e outras práticas silviculturais.

As melhorias obtidas pelo Setor de Pesquisa e projetos de Fomento Florestal não são os únicos responsáveis pelo desenvolvimento da empresa: matéria-prima, as técnicas e processos de produção do papel, a variedade de produtos, os salários, o maquinário constantemente renovado, desgaste das máquinas e não podemos esquecer a participação dos empresários, que tentando garantir e ampliar os niveis de acumulação, se utilizam de formas de atuação, principalmente dentro das fábricas, buscando um crescimento da produção e principalmente de produtividade, fazendo com que se alterem constantemente os métodos de trabalho.

\section{Projeto de Fomento Florestal do Médio Tibagi}

O projeto de Fomento Florestal, assim como os meios utilizados para a sua realização, são os elementos que compõem este item do artigo. Mas para fazer a análise desse Projeto, se faz necessário recorrer a uma referência: 
TRAJANO, N.G. A constituição das Indústrias Klabin.

Para as reservas exigidas pela industria de Monte Alegre mister se fez não apenas adquirir terras de pinhais existentes em propriedades alheias. Quando possuisse madeira de pinho para abastecimento de 25 anos de produção, Klabin do Paraná, poderia despreocupar-se de compras: seus pinheiros plantados estariam crescendo, sendo corfados, num sistema racional e contínuos de renovação dos araucariais (Fernandes, 1974:152).

Esta é uma preocupação da década de 50, quando a fábrica fez uma previsão de que suas reservas florestais dariam para um prazo de 10 anos. Para aumentar essa estimativa fez-se necessário aumentar suas áreas plantadas, numa forma de controlar o fornecimento de matéria-prima para o processo de transformação industrial.

Para garantir a produtividade, efetuada por uma organização sempre crescente da produção, a fábrica vai utilizar de novas técnicas para garantir o ritmo e a intensidade da produtividade.

Surge um regime de parceria entre a indústria e pequenos produtores denominado Projeto Fomento Florestal do Médio Tibagi, com o objetivo de minimizar a compra de grandes áreas utilizadas para o reflorestamento e evitar a formação de extensos blocos homogêneos.

O programa de Fomento Florestal teve início em 1987, quando Klabin, Emater e IAP, iniciaram as primeiras discussões sobre a possibilidade de se desenvolver o projeto, que visa a atingir propriedades localizadas num raio de até $100 \mathrm{Km}$ de distância da Fábrica, são áreas que se encontram inativas, ora pela condição do solo, ora pela política praticada pelo governo em relação à agricultura e que com o reflorestamento poderiam ser incorporadas ao processo produtivo da Klabin.

O programa estabelece as atividades a serem desenvolvidas pelos elementos participantes do projeto, dando legitimidade para o mesmo:

Nomear e distribuir racionalmente tudo

e a todos nos lugares apropriados ao 
TRAJANO, N.G. A constituição das Indústrias Klabin.

\begin{abstract}
desenvolvimento do interesse geral. atribuir competência conforme as capacidades técnicas de cada individuo, delimitar os campos de açâo e as relações possiveis, designar os deveres $e$ as obrigaçôes de uns para com as outros.(Antonacci, 1985:204).
\end{abstract}

A Klabin juntamente com a Emater, têm estimulado os produtores nurais a conduzirem suas propriedades para o reflorestamento, assim para o pequeno produtor esta estratégia surge como uma fonte alternativa de aumentar sua renda familiar.

A finalidade do Projeto é aumentar a produção de matéria-prima para a obtenção do papel, celulose e pasta mecânica, ou direcionar a outras atividades como: lenha, carvão, móveis, vigas para a construção, etc., ou seja, madeira para fins econômicos ou conservacionistas, estabelecendo mecanismos para a promoção da atividade florestal, junto ao pequeno produtor.

A produção de madeira deve ser obtida nos moldes que a Klabin exige, principalmente com relação à técnica aplicada na plantação, com a finalidade de obter madeira de qualidade para ser utilizada como matéria-prima para o processo de industrialização do papel. A plantação adquirindo caracteristicas de funcionamento industrial para a obtenção de lucro.

\title{
Consideraçōes Finais
}

Selecionando elementos da históna da vida desta empresa, deu-se ênfase aos motivos que levaram a família Klabin a montar uma indistria papeleira no sul do pais, relacionando principalmente a adoção de um projeto de Fomento Florestal e a relação entre pequeno produtor e os mecanismos utilizados pelos detentores do capital.

Para tal verificou-se de que forma o processo de crescimento do capital teve sua reprodução garantida. Destacou-se a técnica de dominação da natureza, através do Setor Florestal e a eficácia do mesmo. 
TRAJANO, N.G. A constituįão das Indistrias Klabin.

Em outro momento, mostrou-se a implantação do Projeto de Fomento Florestal no qual o pequeno produtor ganha importância no processo produtivo ao mesmo tempo estabelecendo uma nova relação social baseada na dominação do capital sobre o pequeno produtor.

As normas do Fomento Florestal encobrem os problemas relativos à exploração do pequeno produtor. Porém, para conseguir o consenso através da questão social foi necessário o aval de órgãos do governo, o IAP e a Emater, revestidos de caráter cultural conservacionista e social no sentido de aumentar a renda familiar.

A relação de trabalho do pequeno produtor, toma-se fundamental para a reprodução do sistema, fazendo com que o pequeno produtor coopere de forma indireta do sistema produtivo para o fortalecimento do capital.

Concluindo, procurou-se mostrar a força de um projeto em uma unidade concreta de produção, principalmente desmistificar o discurso empregado nas relações que ali se estabelecem para a expansão e consolidação de uma grande empresa.

\section{Referências Bibliogrảficas}

ALMEIDA, Jozimar Paes de. A extinção do Arco-íris: Ecologia e História. Campinas: Papirus, 1988.

ANTONACCI, Maria Antonieta M. A Vitória da Razão? O IDORT e a sociedade paulista. São Paulo: Marco Zero, 1992.

DECCA, Edgar de. $O$ nascimento das fábricas. São Paulo: Brasiliense, 1982.

DEAN, Warren. A industrialização de São Paulo. São Paulo: Difel, 1981.

FERNANDES, H. Vellozo. Monte Alegre, Cidade de Papel Curitiba: Klabin, 1974.

GRAZIANO DA SILVA, José. Progresso técnico e relações de trabalho na agricultura. São Paulo: Hucitec, 1981.

REICHELL, Heloisa Jochins. "O surgimento de uma grande empresa no parque industrial gaúcho. $O$ caso das indústrias Renner." História e Perspectiva. Uberlândia, V.06. Jan/Jun, 1992. 
TRAJANO, N.G. A constituição das Indústrias Klabin.

PAlADINO, G. Gulineli. Papel, técnica e capital. Curitiba: CEDEPLAR, Dissertação de mestrado, 1985. 